\title{
ROMANIAN
}

NEUROSURGERY

\author{
Vol. XXXIV | No. 2 June 2020
}

Intraneural synovial sarcoma of median nerve.

\section{A rare case report with review of literature}

\author{
Sandeep Bhardwaj, \\ Anil Kansal, \\ Rohit Bansil, \\ Rakesh Singh, \\ Akangsha Sharma
}




\title{
Intraneural synovial sarcoma of median nerve. A rare case report with review of literature
}

\author{
Sandeep Bhardwaj, Anil Kansal, Rohit Bansil, \\ Rakesh Singh, Akangsha Sharma
}

BLK Superspeciality Hospital New Delhi, INDIA

\begin{abstract}
Synovial sarcomas are highly aggressive soft tissue tumour with a poor and dismal prognosis. These tumours have a high propensity for distant metastasis and local recurrence. Although originally believed to arise from synovium, these tumours have been found to occur anywhere in body [1],[2]. We report here, a case of median nerve sarcoma in a 15-year female. This is a rare tumour, which is diagnosed only after histopathological examination with only a few cases reported in the literature (Table 1). Although preoperatively tumour was thought to be a nerve sheath tumour, on histopathology analysis was found to be synovial sarcoma. Despite aggressive behaviour, wide local excision is recommended even in smaller lesions. So, the diagnosis should always be kept in differentials of nerve sheath tumour, as what may be a synovial sarcoma.
\end{abstract}

\section{INTRODUCTION}

Synovial sarcomas may arise from different and unusual sites with distinctive morphological genetic features [3]. They are mostly seen in extremities in young adolescents with male preponderance [4]. It has been found in unusual locations in heart, lung, small intestine, soft palate and peripheral nerves. Only a few cases have been reported in peripheral nerve. Prognosis is poor despite radical surgery, radiation and chemotherapy with 50-60 \% survival [5].

These sarcomas have origin in synovium because of periarticular location, but less than $5 \%$ are continuous with synovium4. Sarcomas have their origin from primitive mesenchymal undifferentiated cells6. Synovial sarcoma is diagnosed on immunohistochemical basis because most of them present as lump or swelling with no clinical or diagnostic features [7]. Translocation $(X ; 18)$ is diagnostic in $90 \%$ of cases [8]. The case presented here is a rare sarcoma arising from median nerve in upper arm. We have described here clinical, radiological features and its management.

\section{CASE PRESENTATION}

A 15 years old female presented with swelling in left arm for last 6

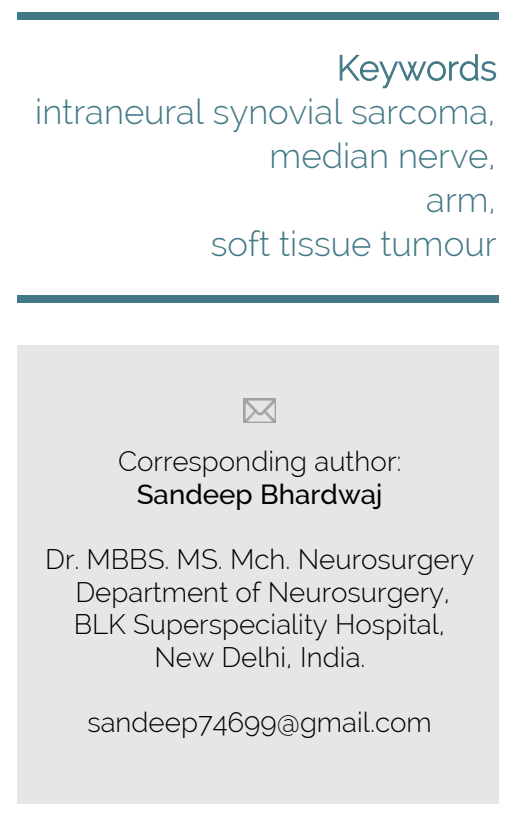

Copyright and usage. This is an Open Access article. distributed under the terms of the Creative Commons Attribution Non-Commercial No Derivatives License (https://creativecommons org/licenses/by-nc-nd/4.0/) which permits noncommercial re-use, distribution, and reproduction in any medium, provided the original work is unaltered and is properly cited.

The written permission of the Romanian Society of Neurosurgery must be obtained for commercial re-use or in order to create a derivative work.

ISSN online 2344-4959 (C) Romanian Society of Neurosurgery

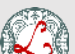

First published June 2020 by London Academic Publishing www.lapub.co.uk 
months with swelling of size of $5 * 4 \mathrm{~cm}$ in left arm which has gradually increased in size. She also complained of pain in left arm radiating along medial aspect of forearm up to left hand. The pain was sharp, and more during night. She also complained of tingling sensation in left upper limb, palm, index and thumb and had history of dropping objects from left hand. On examination, there was decreased sensation along radial three digits with no neurovascular deficit.

The patient was evaluated with Magnetic resonance imaging (Figure 1) which revealed a well encapsulated oval lesion in left upper arm medially burrowing in left biceps and coracobrachialis muscle. The lesion minimally indented the left brachial artery. The lesion was in continuity with median nerve which showed mild enhancement in early and late arterial phase with heterogenous enhancement with non-enhancing / cystic areas in venous and delayed phase. Overall findings were in favour of neurogenic tumour.

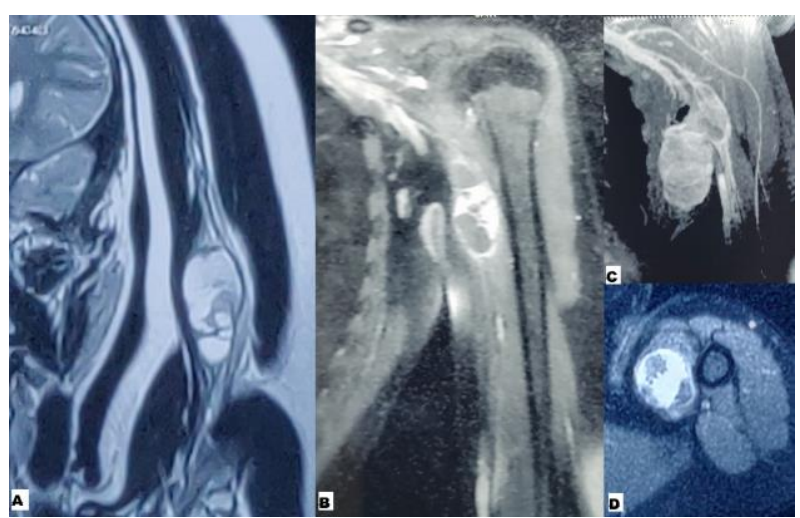

Figure 1.

Electrodiagnostic studies and nerve conduction studies of median nerve were within normal limits. Ultrasound colour Doppler peripheral venous single upper limb was suggestive of hetero-echoic lesion with internal cystic components measuring $43 * 23$ $\mathrm{mm}$ causing compression of underlying axillary artery medially at its lower margin. The patient was taken up for surgical resection with preservation of nerve fascicles. The mass found to be associated intimately associated with nerve, soft in consistency and moderately vascular in nature. Microvsacular excision of mass was done with preservation of nerve fascicles (Figure 2).

On histopathological analysis, tumour was greyish tan made up of spindle cells with sheets of cells with vesicular nuclei and ill-defined cell margins suggestive of mild epitheloid morphology (Figure 3). Focal areas showed perivascular arrangement with cells separated by blood vessels with occasional mitosis and areas of haemorrhage. Collagen and osseous tissue was seen adjacent to tumour. On immunohistochemistry CD 99 was positive, CK negative, Synaptophysin negative, S-100 negative, HMB-45 negative, BCL2 positive and Ki-67 was $15-20$ $\%$ in cellular areas (Figure 4). The histopathological and immunohistochemical analysis were in favour of synovial sarcoma. Post operatively, whole body PET/CECT scan was done for any metastasis and restaging. This was suggestive of small minimally metabolic active solid soft tissue thickening in proximal left biceps muscle indenting left brachial artery probably? residual lesion. Post excision, patient received radiotherapy.

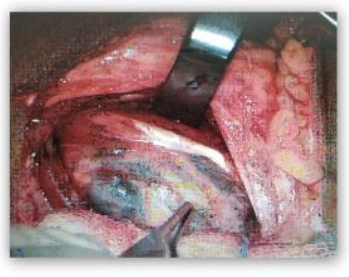

A

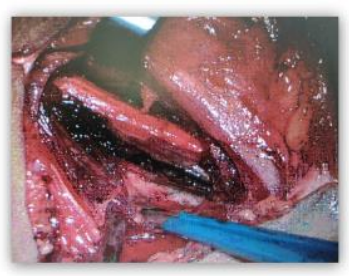

B
Figure 2.

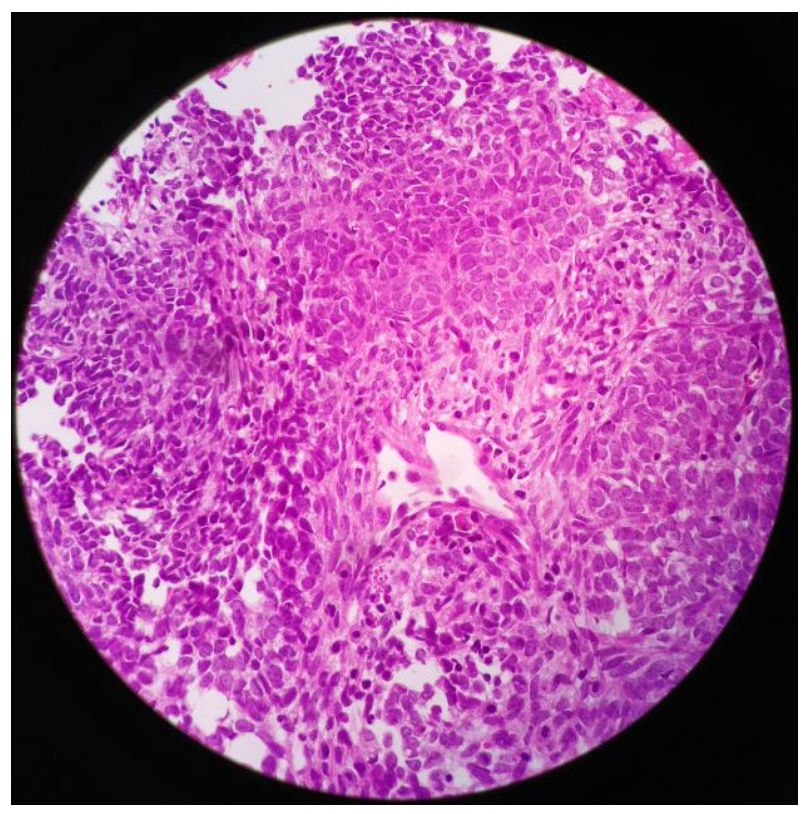

Figure 3. 


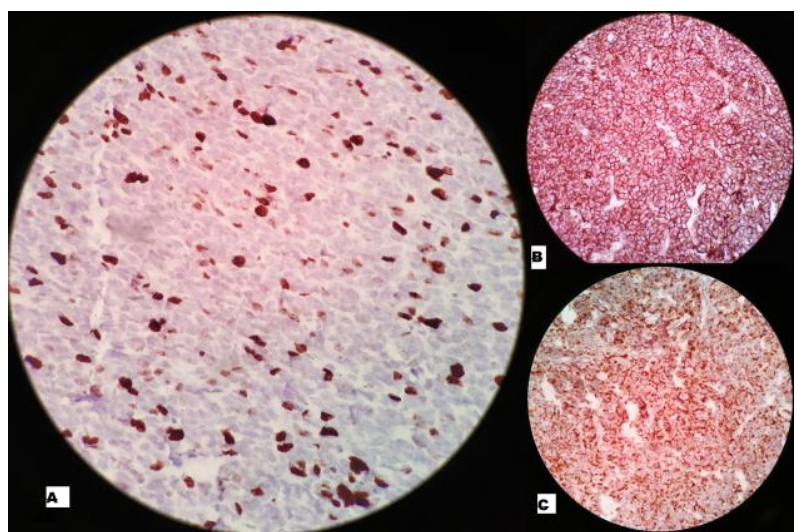

Figure 4.

\section{DISCUSSION}

Synovial sarcomas arising from median nerve are very rare and rarest tumours published in literature. Other sarcomas arising from various nerves reported in literature are from radial, common digital, posterior tibialis, peroneal, facial nerve, S1 root, C7 root and brachial plexus. There are three basic histology features of synovial sarcoma. The most common pattern is biphasic followed by monophasic and poorly differentiated synovial sarcomas. Synovial sarcoma with biphasic type consisted of epithelial cells with fibroblast like spindle cell in various proportions. Monophasic type consists of spindle cells only and are difficult to differentiate from other soft tissue and nerve tumours but now can be differentiated on the basis of immunohistochemical analysis ${ }^{4}$. Third pattern of poorly differentiated synovial sarcomas that has worse prognosis and has also been described ${ }^{6}$. Prognosis of biphasic versus monophasic is still under debate $e^{9,10,11,12}$.

The present case in our study was biphasic synovial sarcoma having both epithelial and spindle cells in various proportions. It was immunohistochemical positive for CD99 and bcl2. The neoplastic proliferation with characteristic SS18SSX1 with chromosomal fusion at molecular level is a feature consistent with diagnosis with synovial sarcoma ${ }^{4}$. Patient was advised for chromosomal analysis, but due to financial constraints patient refused for same. Published cases of median nerve synovial sarcoma with review of literature is summarised in table 1 and table 2 respectively.

Chromosomal translocation is the most efficient way to establish the diagnosis of synovial sarcoma. A gene translocation between chromosomes 18 and $X$ $t(x ; 18)(p 11.2 ; q 11.2)$ occurs in over $90 \%$ of synovial sarcomas ${ }^{4}$. This leads to fusion of one of two variants of the SSX gene with the SYT gene, resulting in either the SYT/SSX1 or SYT/SSX2 chimeric fusion proteins ${ }^{4,6}$. Nearly all biphasic tumours express SYT/SSX1, while monophasic tumours express SYT/SSX1 in approximately half of the cases and SYT/SSX2 in the remainder ${ }^{13}$. Patients with SYT/SSX2 expressing tumours have a significantly better prognosis when compared to those with SYT/SSX1 tumours in terms of rates of metastasis and overall survival ${ }^{13,14,15,16}$.

Factors associated with poor prognosis includes old age, tumour size more than $5 \mathrm{~cm}$, bone, nerve and vascular invasion and poor differentiation with higher mitotic index ${ }^{12,17,18,19}$.Management of synovial sarcoma is wide surgical excision, radiation therapy, and adjuvant chemotherapy which has been found to be correlated to be associated with better prognosis ${ }^{2,20}$
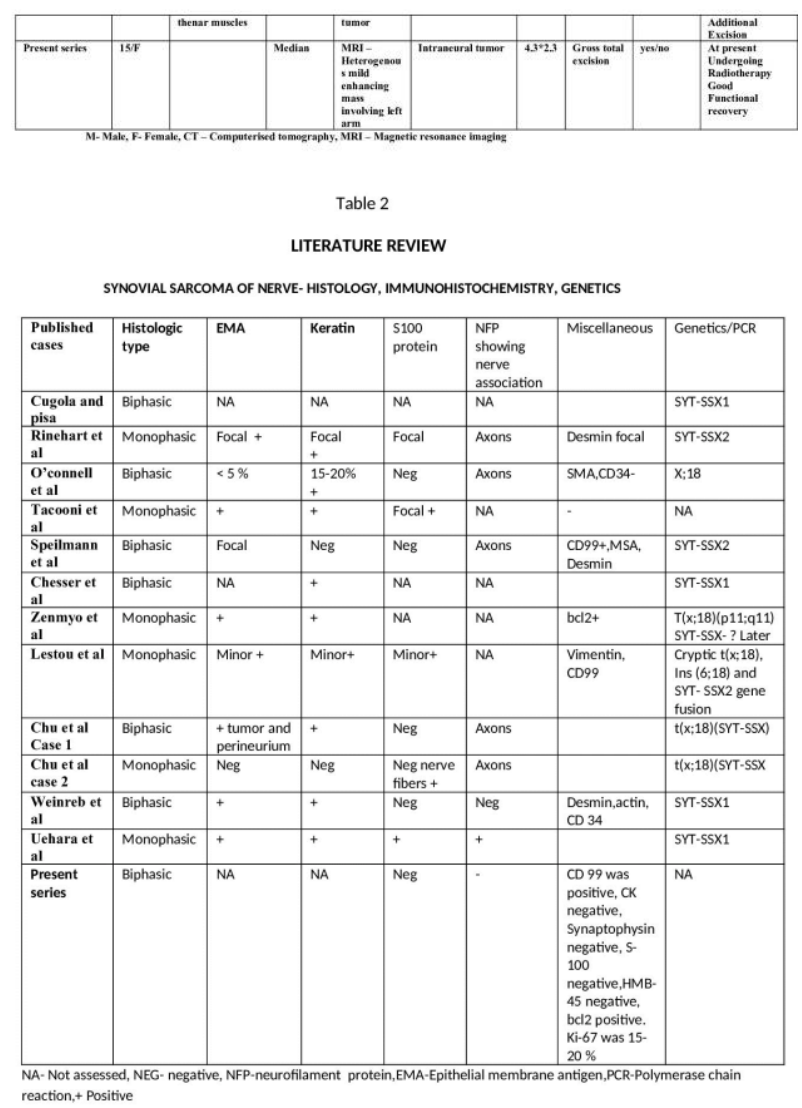

Surgical management followed by radiation and chemotherapy is associated with good prognosis ${ }^{2,20}$. 5-year survival rates of synovial sarcomas have been around $50-60 \%$, in spite of advances in treatment ${ }^{2,21,22}$. Mortality in synovial sarcoma results 
from distant metastasis, most frequently to lung ${ }^{23}$. Radical surgical incision followed by radiation allowed for potential decrease in local recurrence but systemic metastasis remained high even with adjunct chemotherapy ${ }^{24}$.

\section{CONCLUSION}

Synovial sarcoma involving median nerve is a rare and aggressive tumour and is one of the few cases already published in literature. Synovial sarcoma can occur anywhere in our body and should be kept in differentials involving peripheral nerves as in our case. As diagnosis is always made post operative on histo-patholoical analysis with immunohistochemistry, resulting in change in treatment strategy and final outcome of patient. As in our patient, preoperative diagnosis was a benign neurofibroma/schwannoma, we must be aware of aggressive tumour which overall changes the complete treatment and should be always be kept in differentials and managed accordingly.

\section{REFERENCES}

1. Sandberg AA, Bridge JA. Updates on the cytogenetics and molecular genetics of bone and soft tissue tumors. Synovial sarcoma. Cancer Genet Cytogenet.2002:133:123.

2. Guadangnolo BA, Zagars GK, Ballo MT, et al. long term outcomes for synovial sarcoma treated with conservation surgery and radiotherapy . Int J Radiat Oncol Biol Phy. 2007;69:1173-80.

3. Weiss SW, Goldblum JR: Enzinger's and Weiss's soft tissue tumors. 5th ed., Philadelphia, Mosby Elsevier, 2008, 11611182.

4. Fischer C. Synovial sarcoma .Ann Diagn Pathol. 1998;2(2)401-21.

5. Zeren H, Moran CA, Suster S, Fishback NF, Koss MN: Primary pulmonary sarcomas with features of monophasic synovial sarcomas. A clinicopathological, immunohistochemical and ultrasturctural study of 25 cases. Hum Pathol; 26:474-480.

6. Enzinger FM, Weiss SW. Soft tissue tumors. St. Louis: Mosby;1993.synovial sarcoma;pp.757-86.

7. Kransdorf MJ. Malignant soft tissue tumors in a large referral population: distribution of diagnosis by age,sex and location.Am J Roentgenol.1995;164:129-34.

8. Palmerini E, Staals EL, Alberghini M, Zanella L, Ferrari C, Benassi MS, et al. Synovial sarcoma: retrospective analysis of 250 patients treated at a single institution. Cancer. 2009;115:2988-98.

9. Chu PG Benhattar J, Weiss LM, et al. Intraneural synovial sarcoma: two cases. Mod Pathol. 2004;17:258-63.

10. Lewis JJ, Antonescu CR, Leung DH, et al. Synovial sarcoma: a multivariate analysis of prognostic factors in 112 patients with primary localized tumors of the extremity. J Clin Oncol. 2000;18:2087-94.

11. Kawai A, Woodruff J, Healey JH, et al. SYT-SSX gene fusion as a determinant of morphology and prognosis in synovial sarcoma. N Engl J Med. 1998;338:153-60.

12. Trassard $M$, Le Doussal $V$, Hacène $K$, et al. Prognostic factors in localized primary synovial sarcoma: a multicenter study of 128 adult patients. J Clin Oncol. 2001;19:525-34.

13. Kawai A, Woodruff J, Healey JH, et al. SYT-SSX gene fusion as a determinant of morphology and prognosis in synovial sarcoma. N Engl J Med. 1998;338:153-60.

14. Ladanyi M, Antonescu CR, Leung DH, et al. Impact of SYTSSX fusion type on the clinical behavior of synovial sarcoma: a multiinstitutional retrospective study of 243 patients. Cancer Res. 2002;62:135-40.

15. Inagaki H, Nagasaka T, Otsuka T, et al. Association of SYTSSX fusion types with proliferative activity and prognosis in synovial sarcoma. Mod Pathol. 2000;13:482-8.

16. Nilsson G, Skytting B, Xie Y, et al. The SYT-SSX1 variant of synovial sarcoma is associated with a high rate of tumor cell proliferation and poor clinical outcome. Cancer Res. 1999;59:3180-4.

17. O'Connell JX, Browne WL, Gropper PT, et al. Intraneural biphasic synovial sarcoma: an alternative "glandular" tumor of peripheral nerve. Mod Pathol. 1996;9:738-41.

18. Lewis JJ, Antonescu CR, Leung DH, et al. Synovial sarcoma: a multivariate analysis of prognostic factors in 112 patients with primary localized tumors of the extremity. J Clin Oncol. 2000;18:2087-94.

19. Bergh P, Meis-Kindblom JM, Gherlinzoni F, et al. Synovial sarcoma: identification of low and high risk groups. Cancer. 1999;85:2596-607.

20. Choong PFM, Pritchard DJ, Sim FH, et al. Long-term survival in high grade soft tissue sarcoma: prognostic factors in synovial sarcoma. Int J Oncol. 1995;7:161-9.

21. Spillane AJ, A'Hern R, Judson IR, et al. Synovial sarcoma: a clinicopathologic, staging, and prognostic assessment. J Clin Oncol. 2000;18:3794-803.

22. Krsková L, Kalinová M, Brízová $\mathrm{H}$, et al. Molecular and immunohistochemical analyses of $\mathrm{BCL} 2, \mathrm{KI}-67$, and cyclin D1 expression in synovial sarcoma. Cancer Genet Cytogenet. 2009;193:1-8.

23. Enzinger FM, Weiss SW. Soft tissue tumors. St. Louis: Mosby; 1993. Synovial sarcoma; pp. 757-86.

24. Lewis JJ, Antonescu CR, Leung DH, et al. Synovial sarcoma: a multivariate analysis of prognostic factors in 112 patients with primary localized tumors of the extremity. J Clin Oncol. 2000;18:2087-94.

25. Cugola L, Pisa R. Synovial sarcoma: with radial nerve involvement. J Hand Surg (Br) 1985; 10:243-4.

26. Rinehart GC, Mustoe TA, Weeks PM. Management of synovial sarcoma of the median nerve at the elbow. Plast Reconstr Surg 1989;528-32.

27. Tacconi L, Thom M, Thomas DG. Primary monophasic synovial sarcoma of the brachial plexus: report of case 
and review of literature. Clin Neurol Neurosurg 1996;98:249-52.

28. Spielmann A, Janzen DL, O'Connell JX, Munk PL. Intraneural synovial sarcoma. Skeltal Radiol 1997;26:67781.

29. Chesser TJ, Geraghty JM, Clarke AM. Intraneural synovial sarcoma of median nerve. J Hand Surg(Br) 1999;24:3735.

30. Zenmyo M, Komiya S, Hamada T, et al. Intraneural monophasic synovial sarcoma: a case report. Spine 2001;26:310-3.

31. Lestou VS, O'Connell JX, Robinchaud M,et al. Cryptic
$t(X ; 18)$, ins(6;18), and SYT-SSX2 gene fusion in a case of intraneural monophasic synovial sarcoma. Cancer Genet Cytogenet 2002;138:153-6.

32. Weinreb I, Perez-Ordonez B, Guha A, Kiehl TR. Mucinous gland predominant synovial sarcoma of a large peripheral nerve : a rare case closely mimicking metastatic mucinous carcinoma. J Clinical Pathol 2008;61:672-6.

33. Uehara $H$, Yamasaki K, Fukushima $T$, et al. Intraneural synovial sarcoma originating from median nerve. Neurol Med Chir 2008;48:77-82. 